\title{
CARDIAC TISSUE DOPPLER ECHOCARDIOGRAPHIC EVALUATION OF PATIENTS WITH PROLACTINOMA TREATED WITH CABERGOLINE
}

\section{Dr.Mustafa Tasdelen², Dr.Senay Arikan Durmaz ${ }^{1}$, Dr.Nesligul Yildirim ${ }^{3}$, Dr.Aydin Cifci ${ }^{2}$, Dr.Askin Gungunes ${ }^{1}$ \\ ${ }^{1}$ Kirikkale University Faculty of Medicine, Department of Endocrinology, Kirikkale, Turkey \\ ${ }^{2}$ Kirikkale University Faculty of Medicine, Department of Internal Medicine,Kirikkale, Turkey. \\ ${ }^{3}$ Kirikkale University Faculty of Medicine, Department of Cardiology, Kirikkale, Turkey}

\section{Introduction}

There are few side effects of cabergoline which is used for medical treatment of prolactinoma. For this reason, cabergoline is considered as first-line therapy of prolactinoma. However, chronic administration of high dose cabergoline in patients with prolactinoma may be associated with valvular heart disease. The aim of this study is to evaluate left ventricular systolic and diastolic functions by conventional and tissue doppler echocardiography in patients with prolactinoma who have been chronically treated with cabergoline.

\section{Methods}

A total of 30 patients with prolactinoma who have been treated with cabergoline [mean age $33.4 \pm 8.5$ years and body mass index (BMI): $28.1 \pm 7.8 \mathrm{~kg} / \mathrm{m}^{2}$ ] were included in this study. Thirty age- and BMI-matched (mean age $30.0 \pm 9.8$ years; BMI: $26.8 \pm 6.4 \mathrm{~kg} / \mathrm{m}^{2}$ ) hyperprolactinemia patients without cabergoline treatment were also included, and 30 age- and BMI-matched healthy subjects (mean age 31.0 07.0 years; BMI: $25.2 \pm 2.9 \mathrm{~kg} / \mathrm{m}^{2}$ ) were assigned to control group. Cumulative cabergoline dose in patients with prolactinoma was calculated as $218 \mathrm{mg}$. Mean duration of cabergoline therapy was 121.9 \pm 98.5 weeks (range 52-468 weeks). All patients were evaluated by transthoracic and tissue doppler echocardiography. Left ventricle systolic and diastolic functions and left ventricle, left atrium diameters were measured.

All biochemical and hormonal analysis were performed by automatic analyzer.

\section{Results}

According to our data, serum prolactin levels were $35.5 \pm 39.5$ $\mathrm{ng} / \mathrm{ml}$ in prolactinoma group during cabergoline treatment, $58.3 \pm 40.5 \mathrm{ng} / \mathrm{ml}$ in hyperprolactinemia group without cabergoline treatment and $16.2 \pm 8.3 \mathrm{ng} / \mathrm{ml}$ in control group. Left ventricle systolic and diastolic functions parameters were normal among all of the study groups.

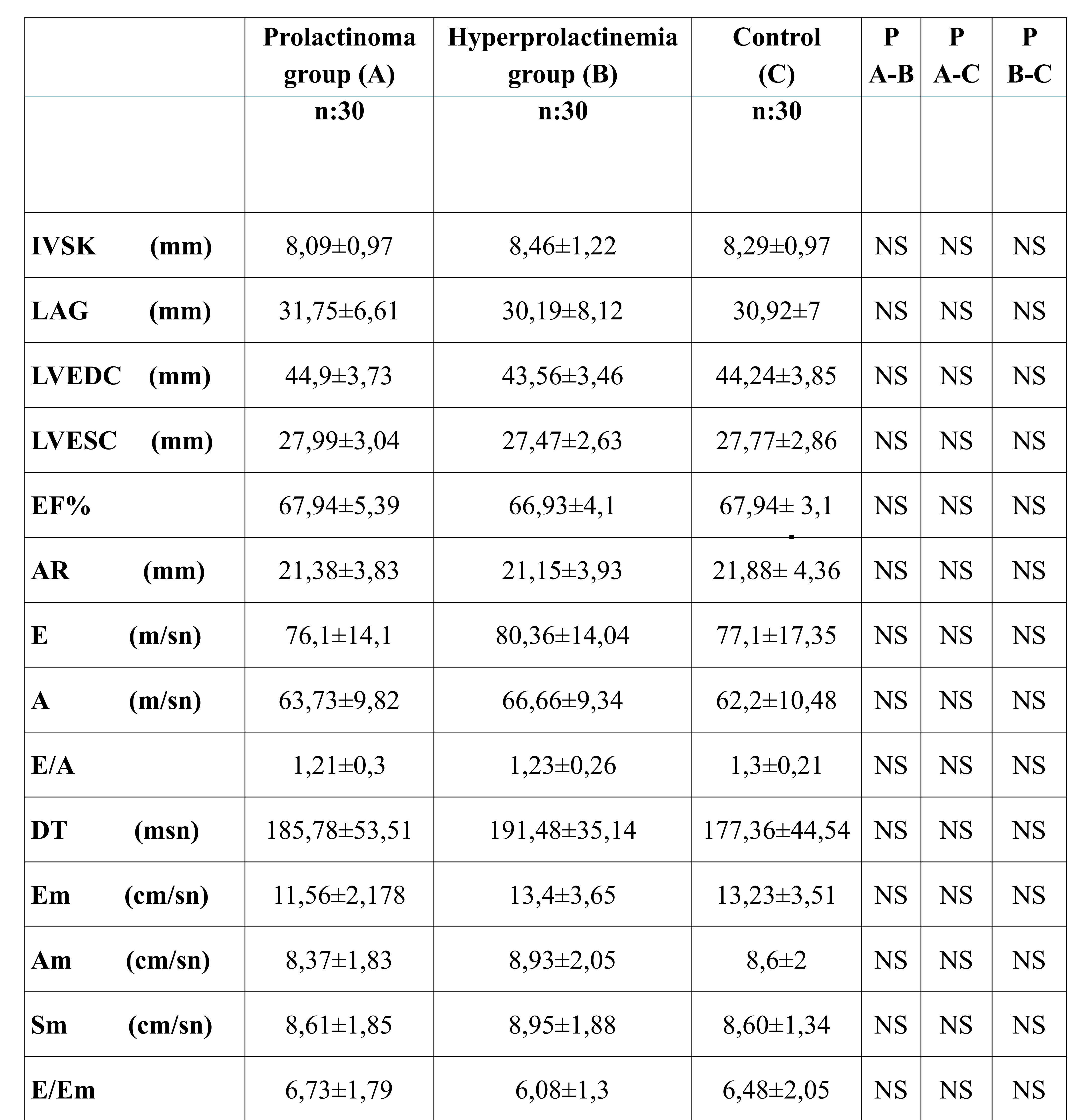

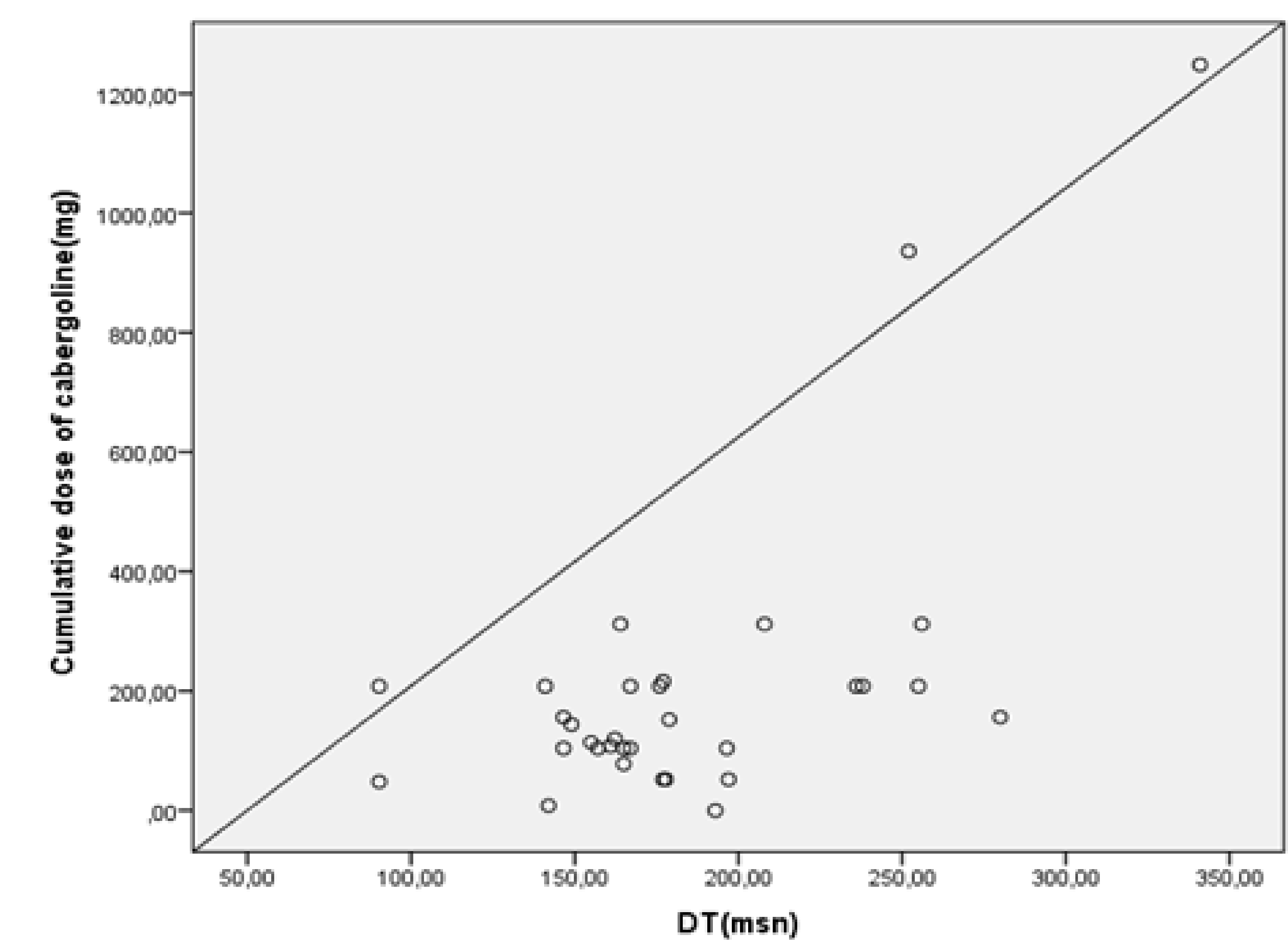

FIGURE 1: Positive correlation between cumulative cabergoline dose and deceleration time (DT) $(\mathrm{r}=0.369, \mathrm{p}=<0.001$

\section{Conclusions}

Low-dose cabergoline in patients with prolactinoma is not associated with cardiac valvular dysfunction and also left ventricular systolic and diastolic dysfunction by conventional and tissue doppler echocardiography. However, high cumulative cabergoline dose may relate to increase in DT and Am parameters that may be related to diastolic dysfunction in the future. 